\title{
IDENTIFICATION OF HPHT-TREATED YELLOW TO GREEN DIAMONDS
}

By Ilene M. Reinitz, Peter R. Buerki, James E. Shigley, Shane F. McClure, and Thomas M. Moses

Examination of recently introduced greenish yellow to yellowish green HPHT-treated diamonds from three companies revealed several identifying characteristics. Gemological properties include a highly saturated body color, well-defined brown to yellow octahedral graining, moderate to strong green "transmission" luminescence to visible light (associated with the graining), and visual evidence of heating. Most of the treated diamonds, including some from each of the three sources, exhibit chalky greenish yellow to yellow-green fluorescence to UV radiation (long- and shortwave). Distinctive features seen with a handheld spectroscope include a $415 \mathrm{~nm}$ line, a strong band from about 480 to $500 \mathrm{~nm}, a$ strong line at $503 \mathrm{~nm}$, and emission lines at 505 and $515 \mathrm{~nm}$. IR spectra reveal that they are type Ia diamonds. Near-IR spectra show a peak at $985 \mathrm{~nm}$, an indicator of high-temperature exposure. A small number of these HPHTtreated diamonds are yellow to brownish yellow; they do not show any green transmission, but other properties identify them as treated.

\section{ABOUT THE AUTHORS}

Dr. Reinitz is manager of Research and Development, and Mr. Moses is vice president of Research and Identification, at the GIA Gem Trade Laboratory, New York. Dr. Buerki is a research scientist, and Dr. Shigley is director, at GIA Research, Carlsbad. Mr. McClure is director of Identification Services at the GIA Gem Trade Laboratory, Carlsbad.

Please see acknowledgments at the end of the article.

Gems \& Gemology, Vol. 36, No. 2, pp. 128-137

(C) 2000 Gemological Institute of America everal companies are now treating brown diamonds with high pressure and high temperature (HPHT) to transform their color to greenish yellow, yellowish green, yellow, or brownish yellow (figure 1). These include the General Electric (GE) Company, Novatek, and unidentified organizations in both Russia and Sweden. Both GE and Novatek are concentrating their efforts on producing colors with an obvious green component (Templeman, 2000; Federman, 2000; Anthony et al., 2000). In contrast, the Swedish manufacturer apparently is trying to produce colors similar to those of natural yellow diamonds (J. Menzies, pers. comm., 2000). Moses and Reinitz (1999) briefly described some of the treated diamonds from these various manufacturers. The present article reports the gemological and spectroscopic properties of a large number of diamonds treated in this fashion, and discusses how the gemological properties compare to those of the rarest and most desirable of the stones that they resemble: natural-color greenish yellow to yellow-green diamonds.

\section{BACKGROUND}

An article by Shigley et al. (1993) on gem-quality synthetic yellow diamonds from Novosibirsk, Russia, described three greenish yellow to yellow synthetic diamonds that had been heat treated at high pressure to alter their color. This treatment was done in the same apparatus in which the diamonds were synthesized. Although the gemological and spectral properties of those synthetics are rather different from the treated-color natural diamonds reported on here, we believe that article was the first report in the gemological literature on HPHT treatment to alter diamond color.

From fall 1996 through winter 1997, approximately 50 natural diamonds of unusual greenish yellow to yellowgreen color were submitted to the GIA Gem Trade Laboratory for identification reports (Reinitz and Moses, 
Figure 1. These diamonds have all been treated at high pressure and high temperature (HPHT).

Clockwise from top right: 1.01 and 0.52 ct diamonds treated by GE; yellow diamonds (0.23-1.01

ct) treated by an unknown source in Sweden; rough diamonds after treatment by Novatek, 0.88-1.68 ct. GE and

Novatek photos by Maha

Tannous; photo of Swedish stones by Elizabeth Schrader.

1997). These diamonds displayed gemological and spectroscopic properties-saturated color, strong graining, burn marks and other visual evidence suggestive of heating, and certain bands in the absorption spectra - that, in light of the current study, suggest that some of them may have been treated using HPHT technology very similar to the current technique. We do not know where those diamonds were treated. However, Van Bockstael (1998) described diamonds with similar colors and gemological characteristics, and stated that they had undergone HPHT treatment in Russia. Henn and Milisenda (1999) reported on similar material, as did De Weerdt and Van Royen (2000). Buerki et al. (1999) wrote a technical report on the spectra and features of both natural and treated type Ia yellow diamonds with green luminescence, and hypothesized as to what kinds of treatment might yield the features observed. Recently, Collins et al. (2000) reported the infrared- and visible-range spectroscopic features of HPHT-treated diamonds, and discussed how the treatment conditions affect the color centers in type Ia diamond.

Both GE and Novatek have been open to discussing details of how they perform these treat- ments (T. Anthony and D. Hall, pers. comms., 2000). Using the same types of apparatus as are used to synthesize single-crystal diamonds, they place natural diamonds under a high confining pressure of about 6 Gigapascals (GPa, equal to 60 kilobars). While the stones are at high pressure, they expose them to high temperatures, up to $2100^{\circ} \mathrm{C}$, for short periods (i.e., less than 30 minutes, in some cases much less). These conditions are similar to those used by GE to decolorize diamonds (Anthony and Casey, 1999), but the starting materials are nitrogen-bearing type Ia brown diamonds, rather than nominally nitrogenfree type Ila diamonds. As with the GE POL decolorization process, however, polished diamonds must be repolished to remove surface damage after HPHT exposure. Although the treated diamonds produced from these two sources are generally similar in appearance and gemological properties, this does not mean that these companies are using identical HPHT equipment and treatment conditions. However, it is not our intention to compare in detail the specific products of the various manufacturers. Rather, this article will focus on those gemological characteristics that will facilitate identification of this kind of treated diamond in general. 


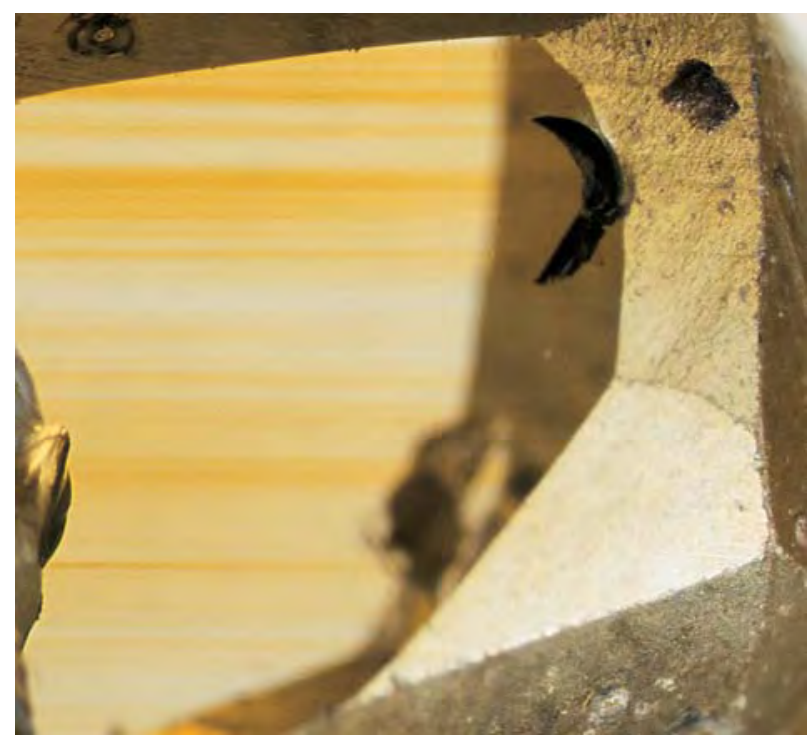

Figure 2. Brown to yellow planar graining was found in most of the treated diamonds examined in this study. Photomicrograph by James E.

Shigley; magnified 10x.

\section{MATERIALS AND METHODS}

For this study, we examined 63 diamonds that were known to have been HPHT treated: 41 faceted (round brilliants and fancy shapes) and 22 rough. Thirty-one of the samples were from GE, 25 were from Novatek (including all 22 rough stones), and seven were from the Swedish manufacturer. Seven of the rough diamonds were examined before and after they were treated by Novatek. We polished small "windows" on 11 of the rough samples (including two of the before-and-after samples) to facilitate examination of their internal features and recording of spectra. All samples were examined with a binocular gemological microscope and various illumination techniques, a long-wave $(366 \mathrm{~nm})$ and short-wave $(254 \mathrm{~nm})$ Ultraviolet Products UV lamp unit, and both a Beck prism and a Discan digital-scanning diffraction-grating spectroscope. Two Hitachi U-4000 series spectrophotometers were used to record absorption spectra at liquid-nitrogen temperature over the range of 250-1000 nm. Infrared spectra were recorded with a Nicolet 760 Fourier-transform infrared (FTIR) spectrometer over the range $400-25,000 \mathrm{~cm}^{-1}$, or a Nicolet 550 FTIR spectrometer over the range 400$11,000 \mathrm{~cm}^{-1}$. Photomicrographs were taken with a Nikon SMZ-U Photomicroscope.

\section{RESULTS}

Description of the Treated Samples. In our overall observations, the diamonds from all three treaters showed comparable properties. On the basis of
TABLE 1. Properties of HPHT-treated diamonds from GE, Novatek, and an undisclosed source in Sweden.

\begin{tabular}{|c|c|c|}
\hline Property & Major group $(57)^{a}$ & Minor group (6) \\
\hline Color & $\begin{array}{l}\text { Greenish yellow to } \\
\text { yellow-green (36); } \\
\text { yellow-green to } \\
\text { yellowish green (21) }\end{array}$ & $\begin{array}{l}\text { Yellow to brownish } \\
\text { yellow }(6)\end{array}$ \\
\hline $\begin{array}{l}\text { Color zoning } \\
\text { (seen in } \\
\text { diffused light) }\end{array}$ & $\begin{array}{l}\text { Brown to yellow } \\
\text { graining (41); none (16) }\end{array}$ & $\begin{array}{l}\text { Brown graining (4); } \\
\text { none (2) }\end{array}$ \\
\hline $\begin{array}{l}\text { Microscopic } \\
\text { features }\end{array}$ & $\begin{array}{l}\text { Etched naturals or } \\
\text { feathers, or tension } \\
\text { fractures, often containing } \\
\text { graphite (32); naturals } \\
\text { without a frosted } \\
\text { appearance (2); no } \\
\text { naturals or fractures (23) }\end{array}$ & $\begin{array}{l}\text { Etched naturals or } \\
\text { feathers (5); no } \\
\text { naturals or fractures (1) }\end{array}$ \\
\hline \multicolumn{3}{|l|}{ UV fluorescence } \\
\hline Long-wave & $\begin{array}{l}\text { Greenish yellow to } \\
\text { yellowish green, strong in } \\
\text { most cases, with a chalky } \\
\text { appearance (39); blue, } \\
\text { plus yellow or greenish } \\
\text { yellow, with a chalky } \\
\text { appearance (17); none (1) }\end{array}$ & $\begin{array}{l}\text { Green to greenish } \\
\text { yellow (3); blue plus } \\
\text { yellow (1); chalky } \\
\text { appearance (4); none (2) }\end{array}$ \\
\hline Short-wave & $\begin{array}{l}\text { Greenish yellow to } \\
\text { yellowish green ( } 53) \text {; } \\
\text { yellow (4); chalky appear- } \\
\text { ance ( } 40 \text { - includes the } \\
4 \text { that showed yellow) }\end{array}$ & $\begin{array}{l}\text { Green to greenish } \\
\text { yellow (3); yellowish } \\
\text { green + blue (3); } \\
\text { chalky appearance (4) }\end{array}$ \\
\hline $\begin{array}{l}\text { Luminescence } \\
\text { excited by } \\
\text { visible light } \\
\text { ("transmission") }\end{array}$ & $\begin{array}{l}\text { Moderate to strong } \\
\text { green (56); moderate } \\
\text { green plus weak blue(1) }\end{array}$ & $\begin{array}{l}\text { None (4); weak blue } \\
\text { plus green (2) }\end{array}$ \\
\hline $\begin{array}{l}\text { Spectroscope } \\
\text { spectrum }\end{array}$ & $\begin{array}{l}\text { Strong } 503 \mathrm{~nm} \text { line ( } 57) \text {; } \\
\text { dark band from } 480-500 \\
\mathrm{~nm}(41)-\text { of these } \\
21 \text { show a } 415 \mathrm{~nm} \text { line } \\
\text { and } 20 \text { show emission } \\
\text { lines at } 505 \text { and } 515 \mathrm{~nm}\end{array}$ & $\begin{array}{l}415 \mathrm{~nm} \text { line (1); no } \\
\text { lines (5) }\end{array}$ \\
\hline $\begin{array}{l}\text { UV-Vis-NIR } \\
\text { absorption } \\
\text { spectra }\end{array}$ & $\begin{array}{l}\text { Weak peak at } 415 \mathrm{~nm} \text {, } \\
\text { strong to very strong peak } \\
\text { at } 503 \mathrm{~nm} \text {, and weak to } \\
\text { strong peak at } 985 \mathrm{~nm} \\
\text { (45); weak broad band } \\
\text { centered at } 550 \mathrm{~nm}(29) \text {; } \\
\text { weak peak at } 535 \mathrm{~nm} \\
\text { (21); weak peak at } 637 \\
\mathrm{~nm}(14) ; \text { or weak peaks } \\
\text { at } 415 \text { and } 503 \mathrm{~nm} \text {, } \\
\text { weak to moderate peak } \\
\text { at } 985 \mathrm{~nm} \text {, and rising } \\
\text { absorption toward } \\
\text { shorter wavelengths (9) }\end{array}$ & $\begin{array}{l}\text { Sharp rise in } \\
\text { absorption toward } \\
\text { shorter wavelengths } \\
\text { with no sharp peaks } \\
\text { (4); or, sharp rise in } \\
\text { absorption toward } \\
\text { shorter wavelengths } \\
\text { with weak peak at } 985 \\
\text { nm (1); weak peaks } \\
\text { at } 415 \text { and } 503 \mathrm{~nm} \text {, } \\
\text { weak to moderate } \\
\text { peak at } 985 \mathrm{~nm} \text {, and } \\
\text { rising absorption } \\
\text { toward shorter } \\
\text { wavelengths (1) }\end{array}$ \\
\hline $\begin{array}{l}\text { Mid-infrared } \\
\text { spectrum } \\
\text { (diamond type) }\end{array}$ & 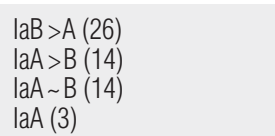 & $\begin{array}{l}l a A>B(2) \\
\mid a B>A(2) \\
\mid a A \sim B(2)\end{array}$ \\
\hline $\begin{array}{l}\text { Other mid-infrared } \\
\text { features }\end{array}$ & $3144 \mathrm{~cm}^{-1}(2)$ & None \\
\hline
\end{tabular}

${ }^{a}$ Number of samples in parentheses. 


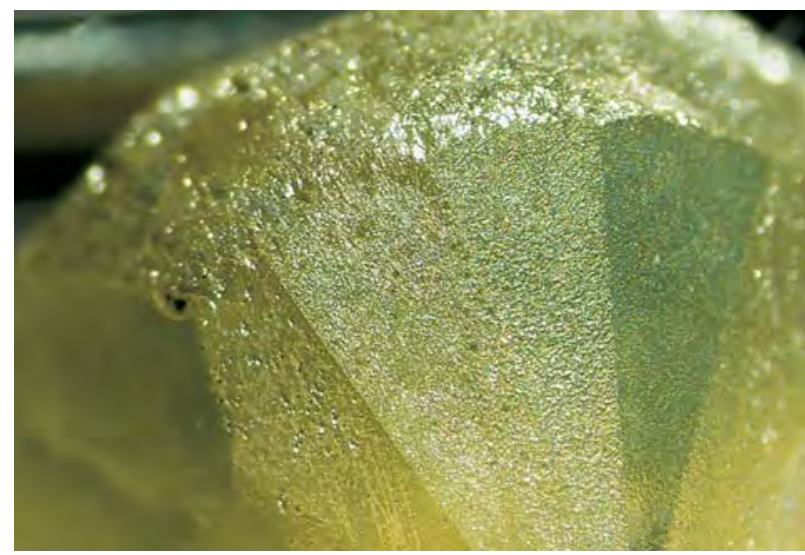

Figure 3. After HPHT treatment, etching and pitting of the surface of this $0.53 \mathrm{ct}$ Novatek diamond obscured the internal features. Fashioned stones always require repolishing after treatment. Photomicrograph by Shane Elen; magnified 10×.

these properties, we found that the 63 samples divided naturally into two groups: those that did or did not show significant green luminescence to visible light (table 1). Because there are many more samples that showed green luminescence (57) than did not (6), we refer to these two groups as "major" and "minor" in table 1.

Color. The colors of all the treated samples were highly saturated (see again figure 1), and many of them were dark in tone. Most were greenish yellow to yellow-green, but six were yellow to brownish yellow. The greenish yellow to yellowish green hues shifted noticeably with different light sources. In particular, direct sunlight excited green luminescence in these diamonds, enhancing the green component considerably. The overall color, including this green luminescence, also was enhanced temporarily (became more saturated) just after the diamonds were exposed to temperatures typical of those used for jewelry repair (up to $1,000^{\circ} \mathrm{C}$ ), but the color reverted to its original appearance as it cooled (T. Anthony, pers. comm., 2000; TMM also observed this color difference in the course of setting one of the jewelry pieces in figure 1).

Features Seen with Magnification. The most common feature seen with magnification (observed in 45 samples) was brown-to-yellow planar graining that was oriented along one or more octahedral directions, forming banded or intersecting patterns of color zoning, as shown in figure 2. This colored graining varied in intensity from weak to very

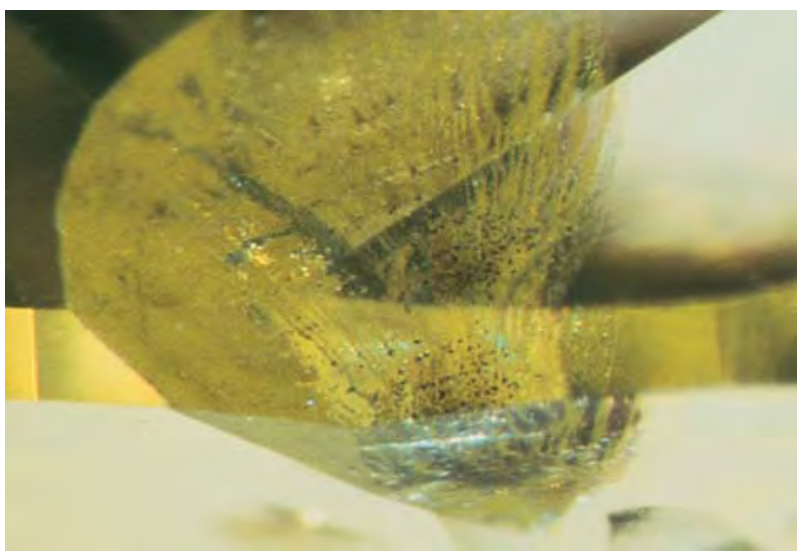

Figure 4. The conditions used for HPHT treatment lead to etching of surfaces that can be observed even after repolishing. Note the translucent, frosted appearance of this fracture. Photomicrograph by Shane Elen; magnified $10 \times$.

strong. The treated rough samples and one fashioned sample (not yet repolished) from Novatek showed etching and pitting of their surfaces (figure 3), which obscured internal features. Eighteen polished diamonds showed microscopic evidence of heating, such as etched and/or pitted naturals, etched or graphitized fractures (figures 4 and 5), or crystalline inclusions with tension fractures around them. Two polished diamonds with small naturals did not show any etching or graphitization.

Figure 5. In some of the diamonds, graphite formed along fracture surfaces during HPHT treatment. Photomicrograph by James E. Shigley; magnified 10×.

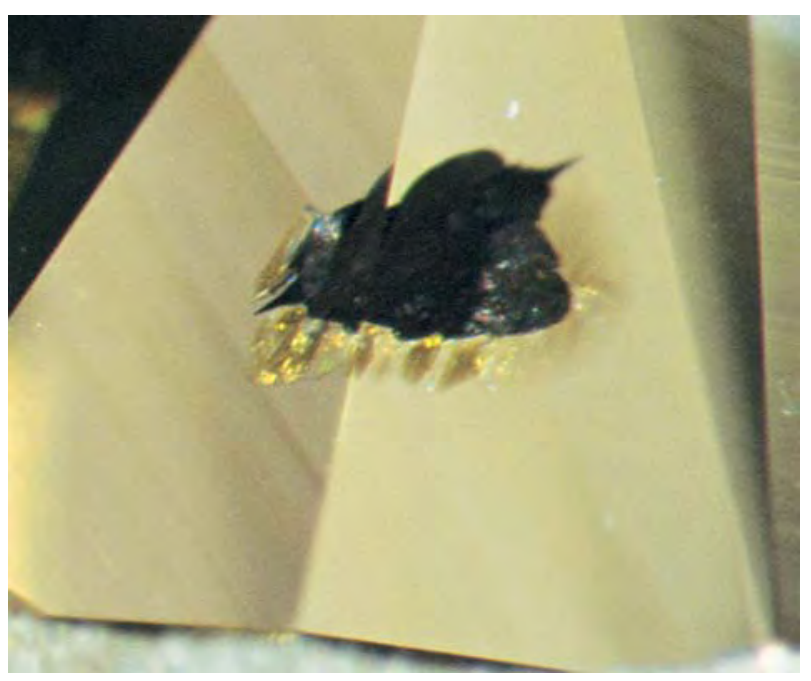




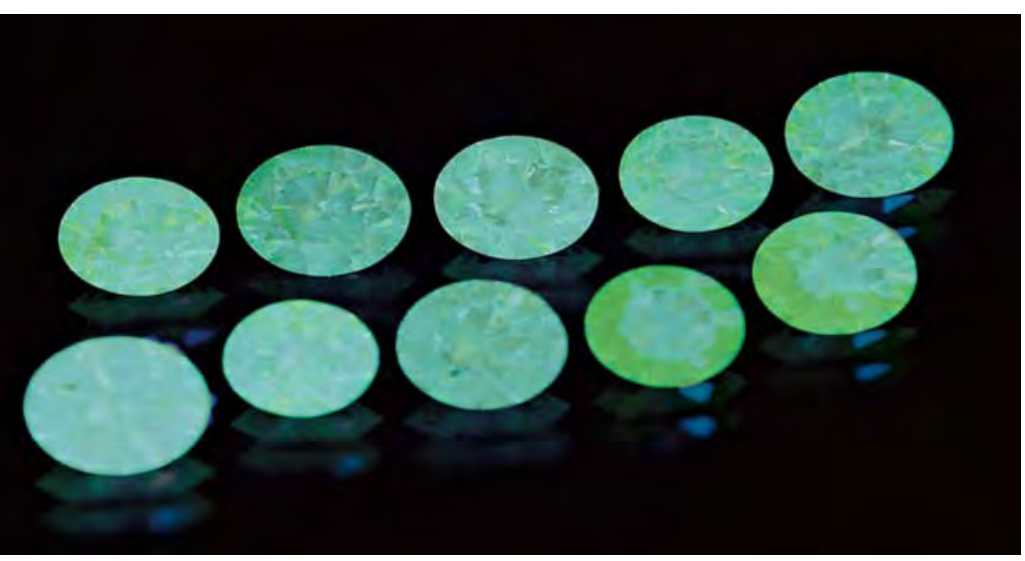

Figure 6. The typical reaction of these treated diamonds $(0.45-0.70 \mathrm{ct})$ to long-wave UV is chalky greenish yellow to yellowish green. Photo by Maha Tannous.

Luminescence. We observed moderate to strong, greenish yellow to yellowish green fluorescence to long-wave UV radiation in $68 \%$ of the greenish yellow to yellowish green samples; the remaining 32\% showed a mixture of blue with yellow or greenish yellow. In 56 of the 63 diamonds, regardless of the fluorescence color, the reaction appeared chalky or hazy (figure 6); in some faceted samples, this chalkiness appeared particularly strong at the culet. The yellow to brownish yellow diamonds showed weaker fluorescence to long-wave UV, in colors similar to those of the other diamonds. When exposed to short-wave UV, $93 \%$ of the greenish yellow to yellowish green samples showed moderate to strong greenish yellow to yellowish green fluorescence, and the remainder fluoresced yellow; 40 of these reactions appeared chalky. The yellow to brownish yellow samples again showed weaker fluorescence in similar colors. In general, the fluorescence was

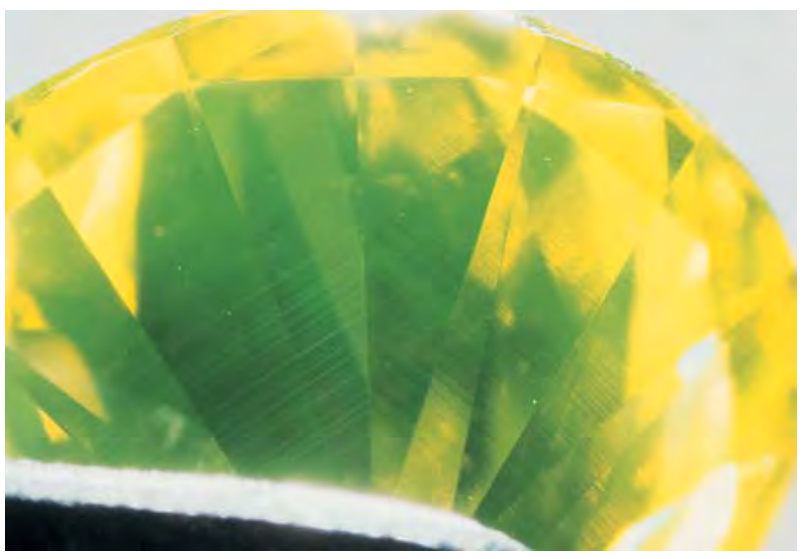

Figure 7. The strong green "transmission" (luminescence to visible light) displayed by these typical HPHT-treated yellow diamonds emanates from graining planes. Photomicrograph by James E. Shigley; magnified 10x.

more intense to long-wave than to short-wave UV, although a few samples exhibited the same intensity to both wavelengths and three that fluoresced weakly to short-wave UV showed no reaction to long-wave UV.

When illuminated by a strong visible light source, such as a fiber-optic lamp, all but the six yellow to brownish yellow samples exhibited moderate to strong green luminescence (green "transmission"). When these diamonds were examined with fiber-optic lighting at $10 \times$ magnification, this luminescence was clearly seen to originate from the brown to yellow planar internal graining in 35 of the 41 samples with graining (figure 7); in some samples, the etched surface prevented observation of the distribution of the green transmission.

Spectra. With a handheld or desk-model spectroscope and transmitted light, we usually saw a strong

Figure 8. The hand or desk-model spectroscope shows a spectrum that is characteristic for most HPHT diamonds: a strong band at about 480-500 $\mathrm{nm}$, a strong line at 503

$\mathrm{nm}$, and sometimes $a$

weak line at $415 \mathrm{~nm}$ and/or emission lines at 505 and $515 \mathrm{~nm}$.

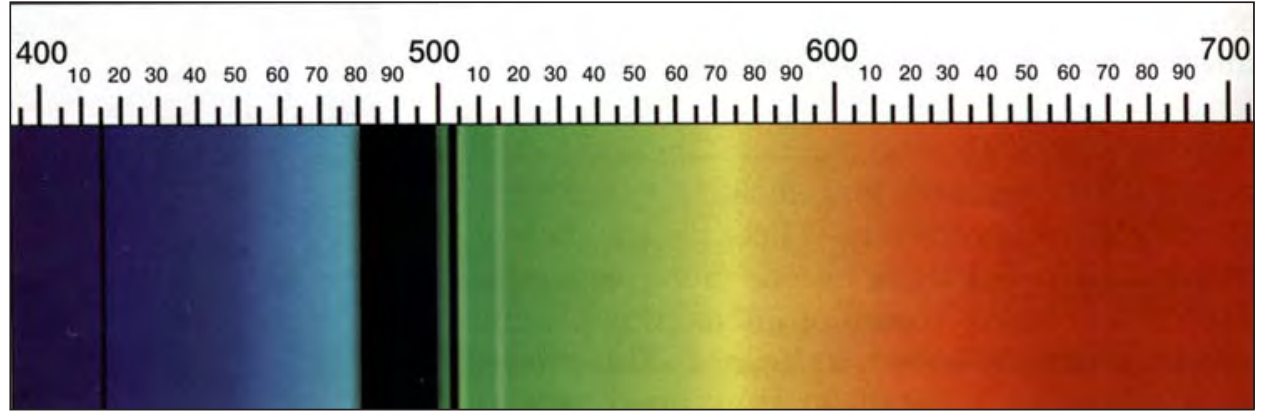


absorption line at $503 \mathrm{~nm}$ and a dark band from about $480-500 \mathrm{~nm}$ in the greenish yellow to yellowish green treated diamonds. A weak to moderate $415 \mathrm{~nm}$ line also was observed in 22 of the samples, including one brownish yellow diamond, and green emission lines at 505 and $515 \mathrm{~nm}$ were seen in 20 samples (not all of which had the $415 \mathrm{~nm}$ line). All of these features are shown in figure 8 . With reflected light, many samples showed a distinct line at $494 \mathrm{~nm}$ and a narrower dark band at a slightly lower wavelength. Five of the yellow samples showed no features in the hand spectroscope.

The UV-Vis-NIR spectra fell into three categories, as shown in figure 9. The most common spectrum (seen in 45 greenish yellow to yellowish green samples; figure 9A) revealed the presence of a weak N3 band (primary line at $415 \mathrm{~nm}$ ), a strong to very strong $\mathrm{H} 3$ band (primary line at $503 \mathrm{~nm}$ ), and a weak to strong $\mathrm{H} 2$ band (primary line at $985 \mathrm{~nm}$ ); the first two lines correspond to those seen in the hand spectroscope. The emission lines observed with the hand spectroscope were not recorded by the spectrophotometer. (See Clark et al. [1992] for a thorough discussion of color centers in diamond, their associated absorption features, and their transformations during annealing.) One or more of three additional features were seen in about half of these samples: a weak to moderate broad peak centered around $550 \mathrm{~nm}$; a weak, sharp peak at $535 \mathrm{~nm}$; and/or a weak, sharp peak at $637 \mathrm{~nm}$ (associated with the NV center). Ten samples (nine greenish yellow to yellowish green and one brownish yellow) showed features similar to those in the first category, but with different relative intensities, overlaid on a steep overall rise in absorbance from about $500 \mathrm{~nm}$ toward the shorter wavelengths (figure 9B). In the third category, five of the six yellow to brownish yellow samples showed a sharp rise toward shorter wavelengths but no N3 or H3 features (figure 9C); only one of these five samples showed an $\mathrm{H} 2$ absorption.

FTIR spectra in the near-infrared range, taken at room temperature, also showed the $985 \mathrm{~nm}$ peak. Although one of our FTIR instruments (the Nicolet 550) detected this feature less well than the lowtemperature visible-NIR spectrometer, the other FTIR instrument detected it with distinctly higher sensitivity. The mid-infrared spectra of all samples showed features typical of type Ia diamonds. The aggregation states of nitrogen varied: Three samples showed A aggregates alone; the remainder showed absorption peaks for both A and B aggregates, with about half showing stronger B-aggregate absorption

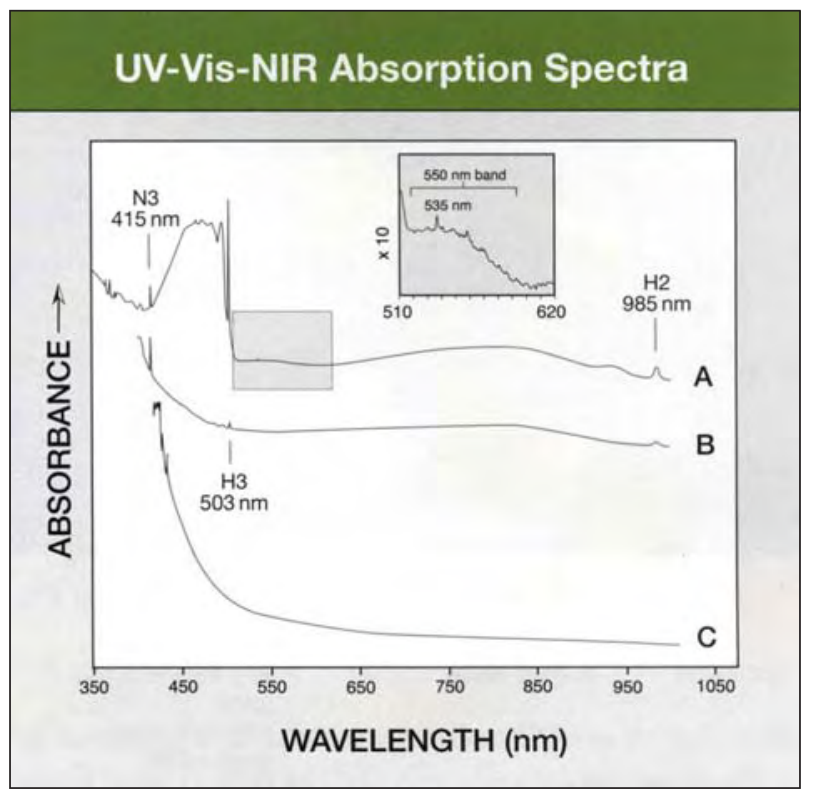

Figure 9. The low-temperature UV-Vis-NIR absorption spectra of these HPHT treated diamonds show some distinctive features. (A) The samples most commonly exhibit weak absorption at the N3 band (415 nm), strong absorption at the H3 band (503 $\mathrm{nm})$, moderate absorption at the H2 center $(985$ $\mathrm{nm})$, and in some cases, a weak to moderate broad peak centered at $550 \mathrm{~nm}$, a weak sharp peak at 535 $\mathrm{nm}$, and a weak peak at $637 \mathrm{~nm}$. A vertical expansion of $10 \times$ is used to emphasize the subtle features between 510 and $620 \mathrm{~nm}$ (see inset). (B) A smaller number of the HPHT-treated diamonds show rising absorption from about $500 \mathrm{~nm}$ toward shorter wavelengths, as well as the N3, H3, and H2 bands. (C) The spectra of the yellow to brownish yellow diamonds showed simply a smooth rise in absorption toward the shorter wavelengths.

and half showing stronger A-aggregate features (Evans, 1992). In several cases, two infrared spectra of the same sample showed slight differences in the relative heights of the A and B aggregate peaks-an indication of the inherently inhomogeneous distribution of nitrogen in diamond. Two samples showed weak absorption peaks at $1344 \mathrm{~cm}^{-1}$, a feature associated with single substitutional nitrogen.

Comparison of Samples Before and After Treatment. The "after" observations of six crystals examined both before and after HPHT treatment and one crystal before and after partial processing (J. Fox, Novatek, pers. comm., 2000) by Novatek 
TABLE 2. Properties of seven diamond crystals, in three color categories, before and after HPHT treatment by Novatek. ${ }^{a}$

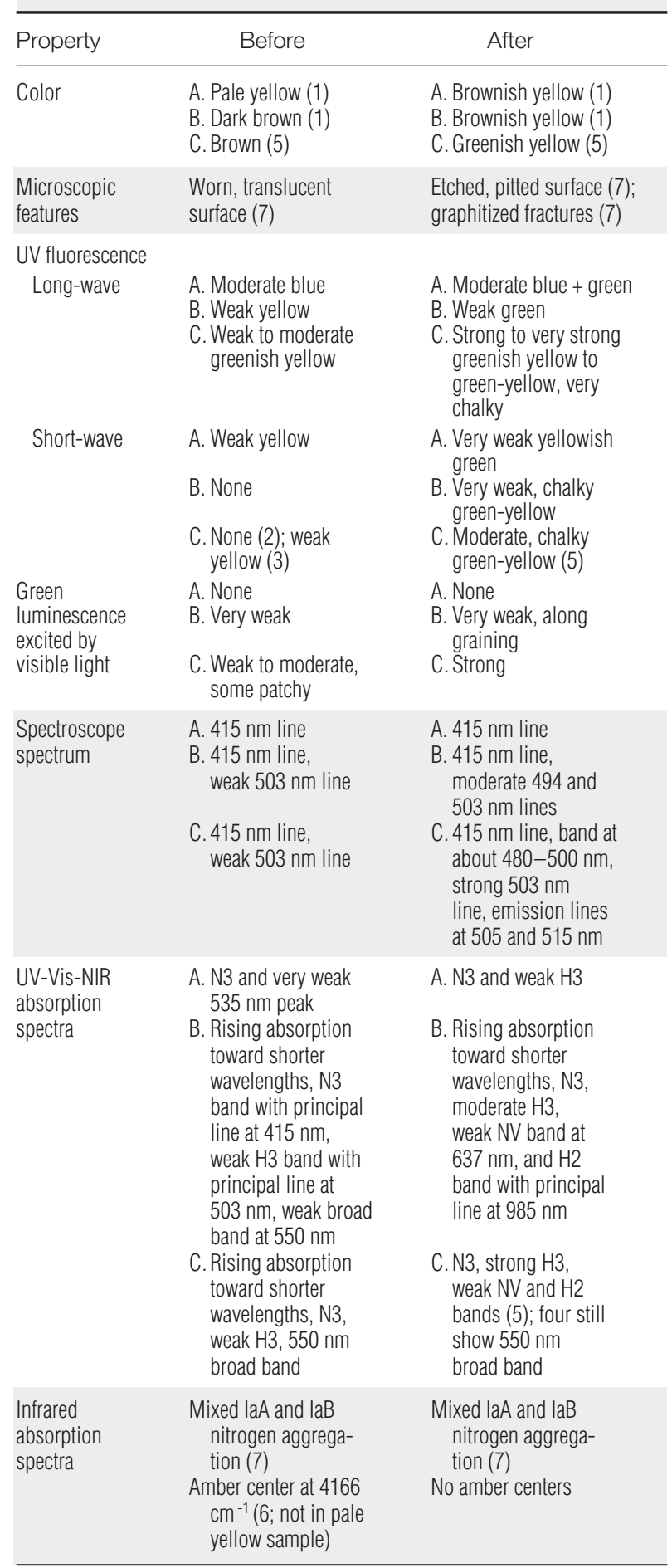

a Where appropriate, results have been categorized (A,B, and $C$ ) according to diamond color. The number of samples is given in parentheses. " $A$ " is the partially processed sample. are included in the results described above. In this section, we will examine how the properties of these samples changed with treatment (see table 2). Both the pale yellow crystal (that underwent partial processing) and a dark brown one were brownish yellow after treatment; the other five changed from brown to greenish yellow (figure 10). Before treatment, all seven had worn, translucent surfaces that obscured the view of the interior; brown graining was observed in the single dark brown sample, one of the two on which a window had been polished. After treatment, all seven crystals had etched, pitted surfaces, and graphitized fractures.

With treatment, the fluorescence to long-wave UV became greener in all seven samples, and it became stronger in both intensity and chalkiness in the five diamonds that turned greenish yellow. The fluorescence to short-wave UV developed or became greener in all seven samples, and increased in both intensity and chalkiness in six samples. Green luminescence to visible light was observed in the six brown crystals before treatment, ranging from very weak to moderate. Green transmission did not develop in the partially processed pale yellow crystal, and it remained weak in the dark brown one. The other five samples showed a substantially stronger green transmission luminescence after treatment. The etched, pitted surfaces prevented us from determining whether this green transmission was zoned along colored graining.

The pale yellow crystal showed no change in a desk-model spectroscope after partial processing. The dark brown crystal showed a stronger line at $503 \mathrm{~nm}$ after treatment, and an additional line at $494 \mathrm{~nm}$. The remaining five samples developed the characteristic spectrum observed in many of the diamonds examined for this study (see again figure 8 and table 2).

The spectra in figure 11 show the effects of treatment in both the UV-Vis-NIR and infrared regions. All seven samples showed production or substantial growth of the peak at $503 \mathrm{~nm}$ related to the $\mathrm{H} 3 \mathrm{cen}$ ter; all but the partially processed sample showed development of smaller peaks at $985 \mathrm{~nm}$ (associated with the $\mathrm{H} 2$ center) and $637 \mathrm{~nm}$ (associated with the NV center; see figure 11A). The mid-infrared spectra showed no significant change in the state of nitrogen aggregation (1333 to $800 \mathrm{~cm}^{-1}$ ), but before treatment the six brown samples showed a structure around $4166 \mathrm{~cm}^{-1}$ (known as the amber center; Du Preez, 1965) that was entirely absent after treatment. A marked reduction of the platelet peak near 

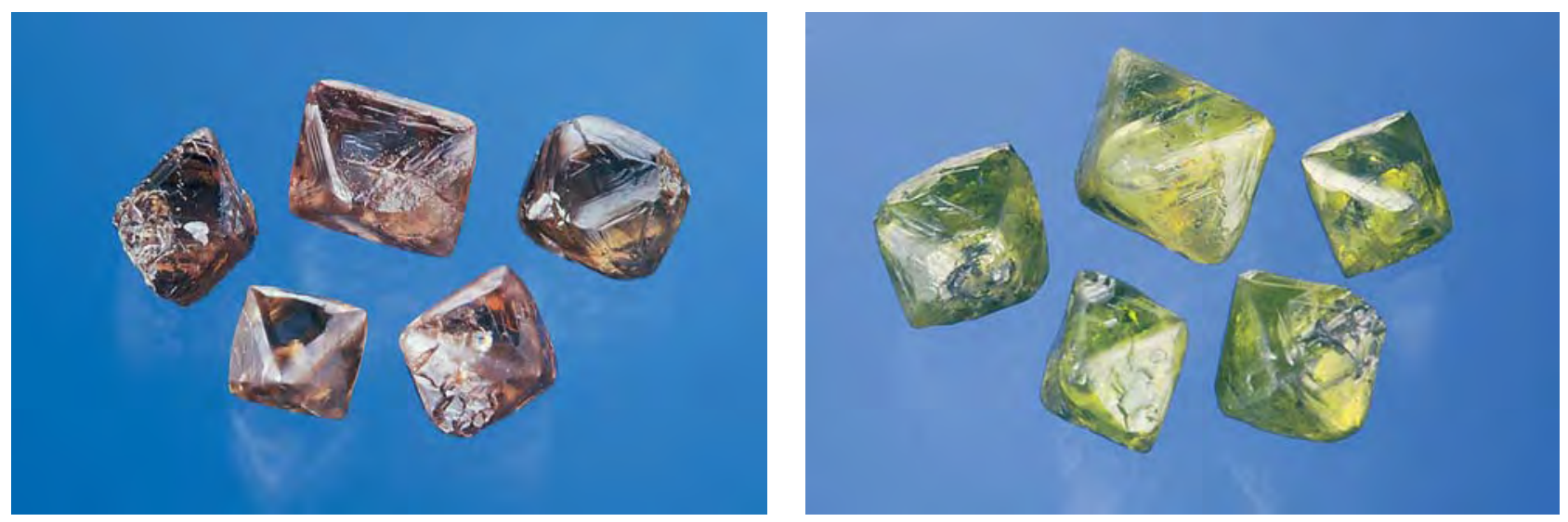

Figure 10. These five diamond crystals (1.90 to $4.45 \mathrm{ct}$ ) changed from brown to greenish yellow due to HPHT treatment by Novatek. Photos by Elizabeth Schrader

$1360 \mathrm{~cm}^{-1}$ was also observed, possibly due to the destruction of a substantial number of platelets (and the associated formation of dislocation loops), as described by Woods (1986).

\section{DISCUSSION}

According to the standard phase diagram for carbon (e.g., Levin et al., 1964), temperatures above $1850^{\circ} \mathrm{C}$ at a pressure of $6 \mathrm{GPa}$ are in the graphite stability zone, where diamond begins to transform into graphite. This transformation does not happen instantly, in bulk, at these conditions. Rather, crys- tal surfaces and fracture surfaces are affected first, resulting in the etching and pitting, as well as graphitization, that we saw in these samples. Collins et al. (2000) suggested that growth of diamond may also occur on the surfaces of crystals during HPHT treatment, if the diamonds are processed in graphite capsules; however, we did not observe any growth features in these samples. In addition, the expansion or contraction of included minerals during HPHT treatment could lead to the formation of tension cracks.

Although the etched surface can be polished

Figure 11. These spectra, taken before and after HPHT treatment by Novatek, provide additional insight into how this treatment transforms the color of brown type Ia diamonds. (A) The UV-Vis-NIR spectra show the development of strong absorptions by the H3 and H2 centers (503 and $985 \mathrm{~nm}$ ), and a weak $637 \mathrm{~nm}$ line (related to the NV center). (B) The mid-infrared spectra show an insignificant change in the ratio of $A$ to $B$ aggregates (1333 to $800 \mathrm{~cm}^{-1}$ ), the disappearance of a peak around $4166 \mathrm{~cm}^{-1}$ (the amber center) and a substantial reduction of the platelet peak (near $1360 \mathrm{~cm}^{-1}$ ) after the HPHT treatment. A vertical expansion of $30 \times$ is used to highlight the peak associated with the amber center (see inset).
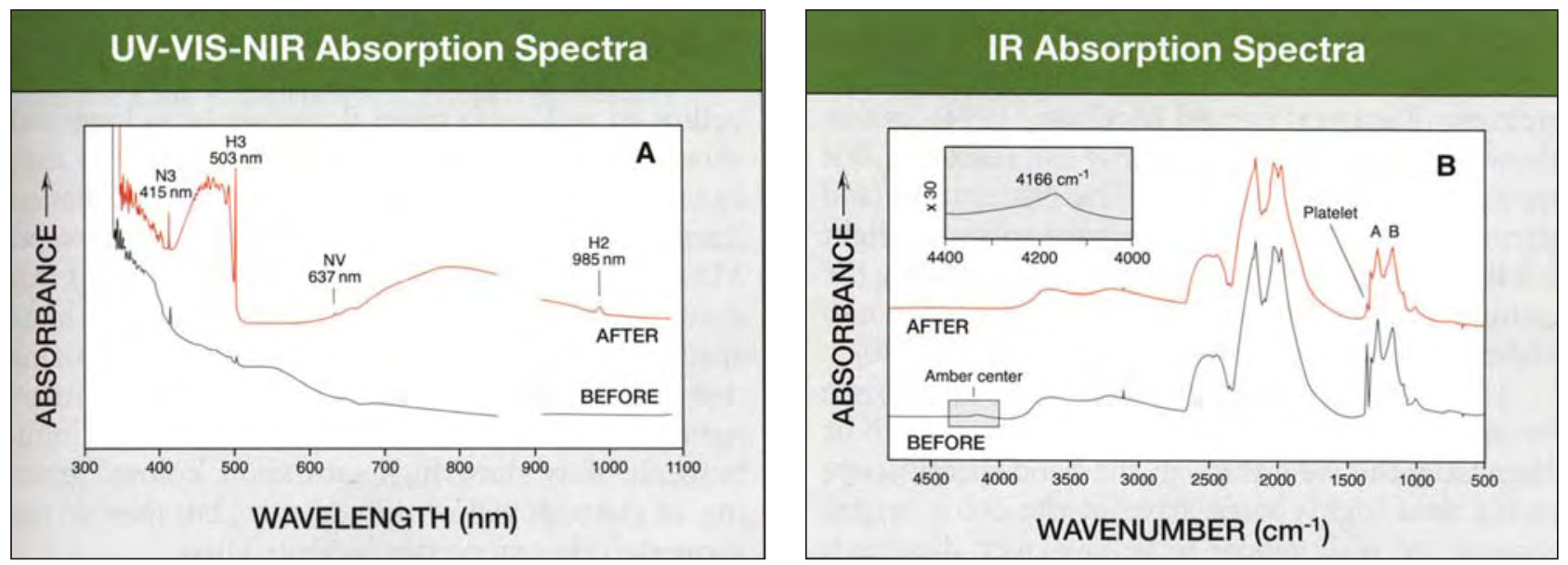
away, remnants sometimes remain at facet junctions and on naturals, and the outer portions of feathers sometimes are etched or graphitized (again, see figures 4 and 5). Experience is necessary to distinguish burned features from the many textures that natural etching produces on diamond. (See Koivula [2000] for photomicrographs of etched textures in natural, treated, and synthetic diamonds.) The presence of etched features or tension cracks is indicative of HPHT processes, but the fact that two samples had naturals that did not appear etched suggests that the lack of such features does not guarantee that a diamond is of natural color.

Brown to yellow graining is presumed to be intrinsic to most of these diamonds, before treatment as well as after. Unlike the type IIa GE POL diamonds that are HPHT treated to eliminate the brown color associated with their graining, most of these type Ia treated diamonds show yellow to brown graining. By comparison, many natural-color yellow, brown, or greenish yellow diamonds exhibit brown graining, but relatively few have yellow graining (Scarratt, 1982).

In our experience, only a fraction of diamonds with a brown to yellow body color exhibit any green luminescence to visible light, and in only some cases is this luminescence strong enough to affect the face-up color. Very high saturation of this combination of yellow and luminescent-green colors is quite rare in natural-color diamonds, although a few such diamonds are known (Moses, 1997).

The moderate-to-strong, chalky, greenish yellow to yellowish green luminescence to both long- and short-wave UV radiation shown by most of these samples provides a simple way to test for the possibility of HPHT treatment, especially for parcels of colored diamonds. In contrast, many natural-color yellow to brown diamonds with green transmission show a combination of blue and yellow fluorescence, often with the yellow emanating from brown graining (Kammerling and McClure, 1994); others show yellow or greenish yellow fluorescence, but typically with no chalkiness. The distribution (and strength) of the green luminescence to visible light is a less reliable indicator, since it is found along the graining both in these treated diamonds and in natural-color yellow to brown diamonds (Kane, 1980).

Although a spectrophotometer is needed to see the spectral details in sufficient completeness to be diagnostic, the view through the hand spectroscope yields data highly suggestive of the color origin. Natural greenish yellow to yellow-green diamonds show a distinct pair of lines at 494 and $503 \mathrm{~nm}$ (due to the $\mathrm{H} 3$ center), and typically show a weak to moderate absorption line at $415 \mathrm{~nm}$ (due to the N3 color center) as well (Maddison and Kammerling, 1993; Moses, 1997). If the diamond is cooled with freon or another apparatus (see, e.g., Hofer and Manson, 1981), a weak line at $595 \mathrm{~nm}$ sometimes can be observed (Scarratt, 1982). This spectrum stands in stark contrast to the dark $480-500 \mathrm{~nm}$ band, strong $503 \mathrm{~nm}$ line, and emission bands at 505 and $515 \mathrm{~nm}$ and/or weak $415 \mathrm{~nm}$ line displayed in the hand spectroscope by HPHT-treated diamonds in this color range.

Our spectral observations, especially those from before and after HPHT treatment (again, see figure 11), generally agree with those of Collins et al. (2000). However, only two of our samples showed the $1344 \mathrm{~cm}^{-1}$ absorption line reported by those authors. The destruction of the amber center by HPHT treatment is quite interesting, and unexplained at this time.

\section{CONCLUSION}

In March 1999, the diamond industry was startled by the news that General Electric Company had developed a process to remove color from brown type IIa diamonds. Similar HPHT technology is being used by several companies on brown type Ia diamonds to produce colors that range from greenish yellow to yellowish green and yellow to brownish yellow. Conclusive identification of these treated-color diamonds requires both infrared and lowtemperature visible spectroscopy, but a number of gemological properties provide some indication of HPHT treatment.

These gemological properties typically include very high saturation and often darker tones of the color; internal yellow to brown graining; etched naturals or fractures, often containing graphite; tension cracks around crystalline inclusions; chalky greenish yellow to yellowish green fluorescence to long- and short-wave UV; and a strong line at $503 \mathrm{~nm}$, a dark band from about 480 to $500 \mathrm{~nm}$, and green emission lines at 505 and $515 \mathrm{~nm}$ visible in the spectroscope. Most of the treated diamonds we examined for this study showed several of these properties; a hand spectroscope is particularly useful for recognizing these colored HPHT treated diamonds. In contrast, natural diamonds with green "transmission" luminescence may show high saturation, colored graining, or greenish yellow fluorescence, but they do not show the other properties presented here. 
Acknowledgments: The authors thank the following persons for loaning treated diamonds for this study: Dr. Tom Anthony of the General Electric Company, Schenectady, New York; David Hall of Novatek, Provo, Utah; and Joseph Menzies of Joseph M. Menzies Inc., New York. We also thank
Matt Hall and Kim Rockwell of the GIA Gem Trade Laboratory for gathering some of the spectroscopic data. This research was supported in part by funds provided by DeBeers, Argyle Diamond Mines Pty. Ltd., and Jewelers' Circular Keystone magazine.

\section{REFERENCES}

Anthony T., Casey J. (1999) Research on diamonds at the General Electric Company. In T.M. Moses, J.E. Shigley, S.F. McClure, M. Van Daele, Observations on GE-processed diamonds: A photographic record, Gems «) Gemology, Vol. 35, No. 3, p. 15.

Anthony T., Casey J., Vagarali S., Shigley J., Moses T., Hall M.S. (2000) GE/POL yellowish green diamonds enter the marketplace. Professional Jeweler, Vol. 3, No. 5, pp. 36, 38, 40-42.

Buerki P.R., Reinitz I.M., Muhlmeister S., Elen S. (1999) Observation of the $\mathrm{H} 2$ defect in gem-quality type Ia diamonds. Diamond and Related Materials, Vol. 8, pp. 1061-1066.

Clark C.D., Collins A.T., Woods G.S. (1992) Absorption and luminescence spectroscopy. In J.E. Field, Ed., The Properties of Natural and Synthetic Diamond, Academic Press, London, pp. 35-80.

Collins A.T., Kanda H., Kitawaki H. (2000) Colour changes produced in natural brown diamonds by high-pressure, high-temperature treatment. Diamond and Related Materials, Vol. 9, pp. 113-122.

De Weerdt F., Van Royen J. (2000) HPHT treated diamonds. Antwerp Facets, No. 34, pp. 36-37.

Du Preez L. (1965) Electron paramagnetic resonance and optical investigations of defect centres in diamond. Ph.D. thesis, University of the Witwatersrand, Johannesburg.

Evans T. (1992) Aggregation of nitrogen in diamond. In J.E. Field Ed., The Properties of Natural and Synthetic Diamond, Academic Press, London, pp. 259-290.

Federman D. (2000) The three-minute rainbow. Modern Jeweler, Vol. 99, No. 3, pp. 34-38, 120-121.

Henn U., Milisenda C.C. (1999) Gemmologische Kurzinformationen: Ein neuer Typ farbbehandelter Diamanten. Gemmologie-Zeitschrift der Deutschen Gemmologischen Gesellschaft, Vol. 48, No. 1, pp. 43-45.

Hofer S.C., Manson D.V. (1981) Cryogenics, an aid to gemstone testing. Gems « Gemology, Vol. 17, No. 3, pp. 143-149.
Kammerling R.C., McClure S.F. (1994) Gem Trade Lab notes: Diamond with unusual color zoning. Gems \&) Gemology, Vol. 30, No. 2, p. 116

Kane R.E. (1980) The elusive nature of graining in gem quality diamonds. Gems e) Gemology, Vol. 16, No. 2, pp. 294-314.

Koivula J.I. (2000) The Microworld of Diamonds: A Visual Reference Guide. Gemworld International, Northbrook, IL, $157 \mathrm{pp}$.

Levin E.M., Robbins C.R., McMurdie H.F. (1964) Phase Diagrams for Ceramists, Volume I (Figures 1-2066). American Ceramic Society, Columbus, OH, p. 47.

Maddison P., Kammerling R.C. (1993) Gem Trade Lab notes: Brown-pink diamond with "green graining." Gems 4 Gemology, Vol. 29, No. 3, pp. 198-199.

Moses T. (1997) Gem Trade Lab notes: Two noteworthy stones from the Americas. Gems \& Gemology, Vol. 33, No. 1, pp. $54-55$.

Moses T., Reinitz I. (1999) Gem Trade Lab notes: Yellow to yellow-green diamonds treated by HPHT, from GE and others. Gems «) Gemology, Vol. 35, No. 4, pp. 203-204.

Reinitz I., Moses T. (1997) Gem Trade Lab notes: Treated-color yellow diamonds with green graining. Gems et Gemology, Vol. 33 , No. 2, p. 136.

Scarratt K.V.G. (1982) The identification of artificial coloration in diamond. Gems \&) Gemology, Vol. 18, No. 2, pp. 72-78.

Shigley J.E., Fritsch E., Koivula J.I., Sobolev N.V., Malinovsky I.Y. Pal'yanov Y.N. (1993) The gemological properties of Russian gem-quality synthetic yellow diamonds. Gems « Gemology, Vol. 29, No. 4, pp. 228-248.

Templeman T. (2000) NovaDiamond introduces new enhancement. Rapaport Diamond Report, Vol. 23, No. 1, pp. 1, 29-30.

Van Bockstael M. (1998) Enhancing low quality coloured diamonds. Jewellery News Asia, No. 169, pp. 320, 322.

Woods G.S. (1986) Platelets and the infrared absorption of type Ia diamonds. Proceedings of the Royal Society of London A, Vol. 407, pp. 219-238. 